\title{
Analysis of the Development Environment of Chinese Basketball Association
}

\author{
Hou Guangqing \\ ( Institute of Physical Education, Changchun Normal University, \\ Changchun Jilin Province, China ) \\ e-mail: hgqing2016@sina.com
}

\begin{abstract}
Chinese Basketball Association is the highest level basketball association in China. Through several seasons' practice and exploration, while encouraging achievements are made, we also face a lot of problems to be solved in the development. In the tide of globalization, in the current macro-historical background of social transformation of China and the gradual transformation of the sport administration system, with the fierce competition of international sport organizations including NBA, we have carefully analyzed the development environment of the Chinese Basketball Association, which is necessary for preparing the responding strategies and development plans.
\end{abstract}

Keywords-Chinese Basketball Association; NBA; CBA ; Development Environment; Strategies

\section{INTRODUCTION}

CBA is the highest level basketball association in China, and has a history of ten years. Since 1995 when CBA started to explore the marketing of basketball, on one hand because CBA had no choices but to save itself, on the other hand, because at that time, the government launched the competition system reform and the business group started to be involved in the basketball sport. In September 2003, the Ten-year Plan for the Reform and Development of Chinese Basketball Association was drafted to point out the direction for the development of CBA and the selected paths. Currently, CBA has its framework and embryonic form as a professional association, and has grown into the best and the most reputed, influential professional association with the best business prospect and the greatest market development potential. The huge basketball market and great growth of basketball in China have attracted many companies and institutions both inside and outside China to invest thereon, and CBA has a great development potential and a huge growth space.

\section{POLITICAL ENVIRONMENT FOR THE DEVELOPMENT}

\section{CBA}

On January 19, Liu Peng, director of General Administration of Sport of China pointed out the following in the work report on the nationwide sport director conference: "it conforms to the operation mechanism of China to pay attention to and study the development dynamics of the world professional sport." [1] which points out the direction for the development of Chinese professional sport and raised the specific requirements, as well as fixed the road to professionalize Chinese basketball. China has already been very important in politics in China, and has undoubtedly become an economic power, however, it has not established equivalent attraction and influence in culture yet, which will significantly affect the improvement of Chinese comprehensive power and its international competition. It is an important task for the development of China in the new age to continue the great cause of reform and open-up, bring the fundamental role of the market economy's allocation of resources into play, promote the development of Chinese culture, and improve China's soft power of culture. Meanwhile, on the international sport stage, Chinese sportsmen's excellent achievements help to greatly improve our image as an influential rising power.

Currently, China's politics is stable, and its power and international status are significantly improved. Beijing's success in holding 2008 Olympic Games, the advances and achievements that China made in the 30-year comprehensive reform and open-up, the launch of the second reform tide signified by "restart-up 30 years after China's reform in villages", and the continued rapid growth and development of China's economy over the next 20 years will all provide important historical opportunities for the increase of the middle-class group and the increase of audience of CBA. These factors will provide a necessary political and environment base for better developing China's sport cause, sport industry and CBA.

\section{ECONOMIC ENVIRONMENT FOR DEVELOPING CBA}

Since the reform and open-up, Chinese economy undergoes a continuous growth, and with the effective macro-control and guidance of the government, the annual average growth of GDP is up to $9.3 \%$, making a record in the world economic development history [2]. According to the prediction of a research report by Goldman Sachs in 2003 Dream Together with BRICS: Look into 2050, in the next 50 years, Brazil, Russia, India and China will become a very powerful force.

Now, China's industrialization and socialization process is accelerated, and the high growth of China's economy will surely drive the rapid change of the social hierarchy of China, and the greatest change is the rapid increase of the middle class groups. The middle class group likes new things and has a higher expectation of life quality and taste. However, the main consumption group of CBA and the basketball market is the middle class group, and their expansion will undoubtedly bring great endogenous power to the sustainable development of CBA.

The environment of sustainable stable growth of Chinese economy and the rapid growth of middle class group will create a great investment and consumption 
environment for the development of CBA. We have a huge number of basketball fans and a great basketball consumption market, in particular, there are 465 million youngsters in China, accounting for $36.25 \%$ of the total popular. Most of them like basketball, and are active consumers of various basketballs, which provides a hardwon opportunity and growth space for the foreign basketball institutions' investment on China's basketball industry and market.

China's huge basketball market and its great growth have attracted a lot of foreign and domestic enterprises and institutions. NBA and Infront have showed their sincerity of cooperation with $\mathrm{CBA}$ and desire to invest on Chinese basketball. Basketball sport is attracting more and more attentions in China and CBA has a great potential of development and a huge growth space.

\section{SOCIAL ENVIRONMENT FOR THE DEVELOPMENT OF CBA}

Under the circumstance of stable politics and prosperous economy, despite the problems in the transformation of China's society, Chinese society is very stable. In recent years, the central government attaches great importance to the issue of "village, agriculture and peasant", not only exempts the agricultural taxes and duties, and seriously punishes the arrears of wages, but also attaches great importance to the peasants' work in cities and their children's going to school and so on, and has improved the peasants' life; the urban social guarantee system is also gradually improved to form the comprehensive social guarantee system covering pension insurance, medical insurance, unemployment insurance and basic cost of living allowances[3]. At the same time, the government make great efforts to rectify the police order, and combat evil forces, and effectively improve the security environment and purify the spirit of the society. The measures that the government takes effectively relieve the social conflicts, and reduce the instable factors of the society so that the people's security is greatly improved. Currently, the stable social environment of China is also advantageous for accelerating the development of the sport industry and CBA.

Now, Chinese society is in the middle and late stage of industrialization and the urbanization is being accelerated, the economy develops fast, the society is stable and the culture is prosperous, people's demand for basketball sport as a merchandise grows rapidly, and most clubs of CBA have earned a lot of social benefits and economic benefits from the investment on basketball. Many clubs have made money from the investment, and the average annual wage of the basketball players in the association is about 200300 thousand Yuan, and the every star player's income from wages and others amount to more than one million Yuan, and most owners of clubs have earned a lot of social benefits from basketball.

Currently, CBA develops stably with great social image, and are highly thought of, and now has a lot of faithful fans. In terms of building the system of association, the rules and regulations are continuously improved and standardized. Although there have been occasionally problems occurring, Chinese Basketball Association is still very open and transparent, and deals with all of the issues fairly, and completely put all of things under their management and control, in particular their attitudes, abilities and levels shown in crisis intervention, and acts as an excellent model for other associations.

\section{SPORT ENVIRONMENT FOR THE DEVELOPMENT OF CBA}

Although CBA has a short history of reform and development and there are a lot of problems to be urgently solved, it now has established its framework and embryonic form, and CBA has grown into a highly reputed and most influential professional association with the best image in China and the greatest commercial prospect and huge potential for market development[4]. Meanwhile, globally influential stars such as Yao Ming appear in the field of basketball in China. They are not only skilled in playing basketball, but also live a healthy life, as well as have a passion for public activities, are prepared to take social responsibilities and create a huge quantity of treasures for the society. The success in holding the 2008 Beijing Olympic Games, and Chinese Sport Delegate's winning 51 gold medals as well the national men and women basketball teams' excellent performance in Beijing Olympic Games make a great influence on the international society. The advantage of China's socialist system becomes much more outstanding because of the tremendous success of the Olympic Games, and the great achievements of the reform and open-up of China are fully displayed; Chinese excellent traditional humanistic ideas are further spread, and positive international opinions are formed on the comprehensive development of Chinese sport by building the sport information platform. A strategic opportunity is created for widely and permanently holding sports events, and a broad development space is brought to CBA. The consortiums from all over the world have set their sights on the rapidly rising sport industry in China after Beijing Olympic Games, and Beijing Olympic Games is driving the sport industry of China and CBA to develop rapidly in the two aspects of investment and consumption [6]. We can say that the great environment for sport development inside and outside China is a very hard-won historical opportunity for accelerating the development of CBA, in particular for introduction of strategic investment, accelerating the innovation and reform of the system, optimizing the structure of CBA, and rapid upgrading of the $\mathrm{CBA}$ chain.

\section{CONCLUSIONS}

There are favorable political environment, economic environment, social environment and sport environment for the reform and development of CBA, and it has its own advantages for its development, and faces a good opportunity for its development. Meanwhile, CBA must be aware of its limitations. The development strategy of CBA should be: being based on itself, by virtue of external forces instead of relying on external forces, developing independently, further improving the base and overall power for the development of CBA, and further cooperating with overseas institutions to develop the Chinese basketball market in an open attitude, 
transforming the ideas, improving the consciousness of service, insisting the principle of being managed by the government and market operation.

\section{REFERENCES}

[1] Rob Simmons. Mixing the princes and the paupers: Pay and performance in the National Basketball Association[N].Labour Economics,2011-10-21(6)

[2] Xu Yong-gang, Dai Yongguan. Comparison and Analysis of the Cultural Level of CBA and NBA[J]. Journal of Wuhan Institute of Physical Education, 2015(1)16-18

[3] James J Zhang, Eddie TC lanm, Cianforne, etc. An importanceperformance analysis of media activities associated with WMBA game consumption[N]. Sport Management Review,2014-12-9(3)

[4] Michael E Pfahl, Audrew Kreutzer, Mike Maleski,etc. If you build it, will they come? Acase study of digital space and brand in the National Basketball Association[N]. SportManagemenReview,2012-2-9(3)
[5] Zhang Wen-jian, Evolution and Innovation of the Professional Sport Organizations [M].Beijing: Press of Beijing Sport University, 2014

[6] Zhao Jian. Construction of the Marketing Model of the Relationship of CBA [J].Shandong Administration of Sports.2015(3):53-55

[7] Jin Yong. About the Influence of the Reform of Competition Rules on the Process of Professionalization of CBA [J].Journal of Xi'an Physical Education Unversity.2014 (2):28-30

[8] Roger G. Noll and Andrew Zimbalist. The Eeonomic Impact of Sports Teams and Stadiums[M].washington,DC: The brooking Institution 1997

[9] Wang Xiao-hua, Chen Denghui. Enlightenment of the Growth of NBA on the Development of CBA Clubs [J]. Journal of Beijing University of Physical Education 2012(8):1146-1148

[10] Hu Li-jun, Research into the Development of CBA during the Transformation of the Society.[D], Beijing Sport University, 2013 